\title{
Empirical prediction for travel distance of channelized rock avalanches in the Wenchuan earthquake area
}

\author{
Weiwei Zhan, Xuanmei Fan, Runqiu Huang, Xiangjun Pei, Qiang Xu, and Weile Li \\ State Key Laboratory of Geohazard Prevention and Geoenvironment Protection, Chengdu University of Technology, \\ Chengdu, 610059, China
}

Correspondence to: Xuanmei Fan (fxm_cdut@qq.com)

Received: 24 November 2016 - Discussion started: 2 December 2016

Revised: 22 April 2017 - Accepted: 2 May 2017 - Published: 8 June 2017

\begin{abstract}
Rock avalanches are extremely rapid, massive flow-like movements of fragmented rock. The travel path of the rock avalanches may be confined by channels in some cases, which are referred to as channelized rock avalanches. Channelized rock avalanches are potentially dangerous due to their difficult-to-predict travel distance. In this study, we constructed a dataset with detailed characteristic parameters of 38 channelized rock avalanches triggered by the 2008 Wenchuan earthquake using the visual interpretation of remote sensing imagery, field investigation and literature review. Based on this dataset, we assessed the influence of different factors on the runout distance and developed prediction models of the channelized rock avalanches using the multivariate regression method. The results suggested that the movement of channelized rock avalanche was dominated by the landslide volume, total relief and channel gradient. The performance of both models was then tested with an independent validation dataset of eight rock avalanches that were induced by the 2008 Wenchuan earthquake, the $M_{\mathrm{S}}$ 7.0 Lushan earthquake and heavy rainfall in 2013, showing acceptable good prediction results. Therefore, the traveldistance prediction models for channelized rock avalanches constructed in this study are applicable and reliable for predicting the runout of similar rock avalanches in other regions.
\end{abstract}

\section{Introduction}

Rock avalanches are extremely rapid, massive flow-like movements of fragmented rock from a very large rockslide or rockfall (Hungr et al., 2014). Hundreds of rapid and long runout rock avalanches were triggered by the 2008
Wenchuan earthquake in Sichuan Province (Zhang et al., 2013), with catastrophic consequences for residents in the affected areas. For instance, the $15 \times 10^{6} \mathrm{~m}^{3}$ Donghekou rock avalanche in Qingchuan County, near the seismogenic fault, traveled $2.4 \mathrm{~km}$, killing about 780 people and destroying four villages (Zhang et al., 2013). Rock avalanches can cause incredible damage due to their high-speed and unexpectedly long runout, but their transport mechanisms are still considered to be controversial among many researchers (Hungr et al., 2001). Therefore, constructing prediction models for rock avalanche travel distance is meaningful in terms of not only theoretical research on motion mechanisms but also practical application for risk mitigation of rock avalanches.

Methods for determining the travel distance of landslides can be divided into two categories: dynamic modeling (Heim, 1932; Sassa, 1988; Hungr and McDougall, 2009; Pastor et al., 2009; Lo et al., 2011) and empirical modeling (Scheidegger, 1973; Lied and Bakkehøi, 1980; Corominas, 1996; Finlay et al., 1999; Van Westen et al., 2006; Guo et al., 2014). The dynamic models are able to provide information on landslide intensity, such as velocity, affected area and deposition depth, in addition to travel distance. Nonetheless, dynamic models with a variety of physical bases require accurately quantified input parameters that are difficult to obtain before the events, and many simplified assumptions that are not applicable to the actual situation. Recently Mergili et al. (2015) developed the multi-functional open-source tool r.randomwalk for conceptual modeling of the propagation of mass movements, which can combine the empirical model with the numerical model. Empirical models considering the correlations between observational data provide an effective technique to aid in understanding mech- 


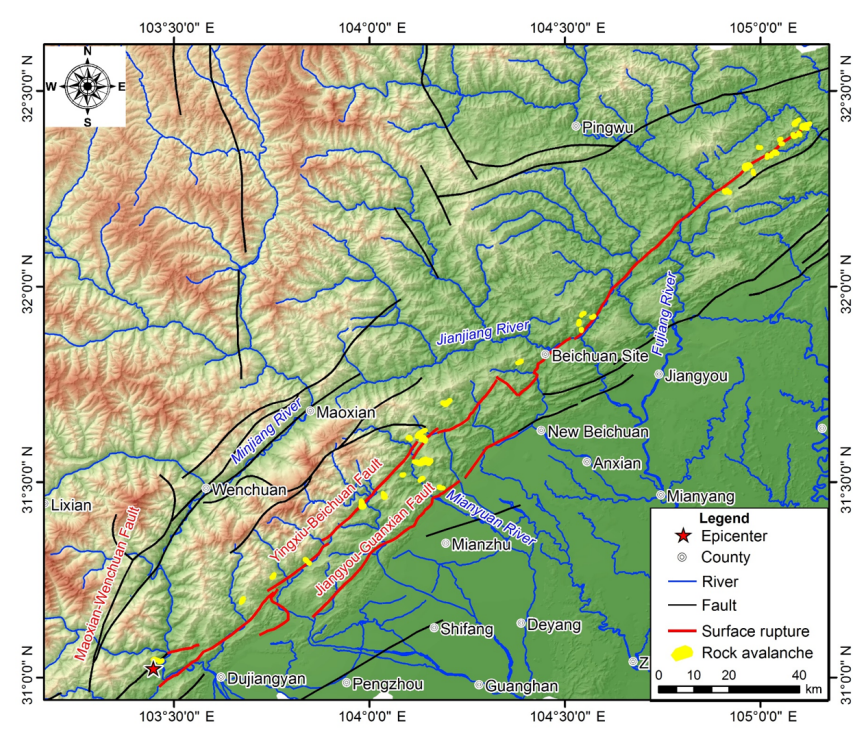

Figure 1. Distribution map of large rock avalanches triggered by the Wenchuan earthquake.

anisms of rock avalanche motion and to develop practical models for predicting rock avalanche travel distance. However, the empirical-statistical models set up from samples with different geomorphological and geological surroundings, trigger conditions or failure modes are not very sufficient to be applied to the Wenchuan earthquake area.

In this study, we compiled a dataset of 38 rock avalanches with flow paths confined by channels (this kind of landslide is hereinafter termed channelized rock avalanche) from interpretation of remote sensing, field investigations and literature review (see Sect. 3.1). Statistical correlations were used to determine the principle factors affecting the mobility of the channelized rock avalanches. Then a stepwise multivariate regression model was developed to build a best-fit empirical model for the travel-distance prediction of this kind of rock avalanches in the Wenchuan earthquake area. A derivative multivariate regression model was also constructed. The performance of both models was then tested with an independent validation dataset of eight rock avalanches in the same area.

\section{Rock avalanches in study area}

The study area (see Fig. 1) is on the northeast-trending Longmenshan thrust fault zone between the Sichuan basin and the Tibetan plateau. Three major sub-parallel faults are the Wenchuan-Maowen fault, the Yingxiu-Beichuan fault and the Pengguan fault (Fan et al., 2014). With long-term endogenic and exogenic geological process, this region is characterized by high mountains and deep gorges with extreme rates of erosion (Qi et al., 2011).
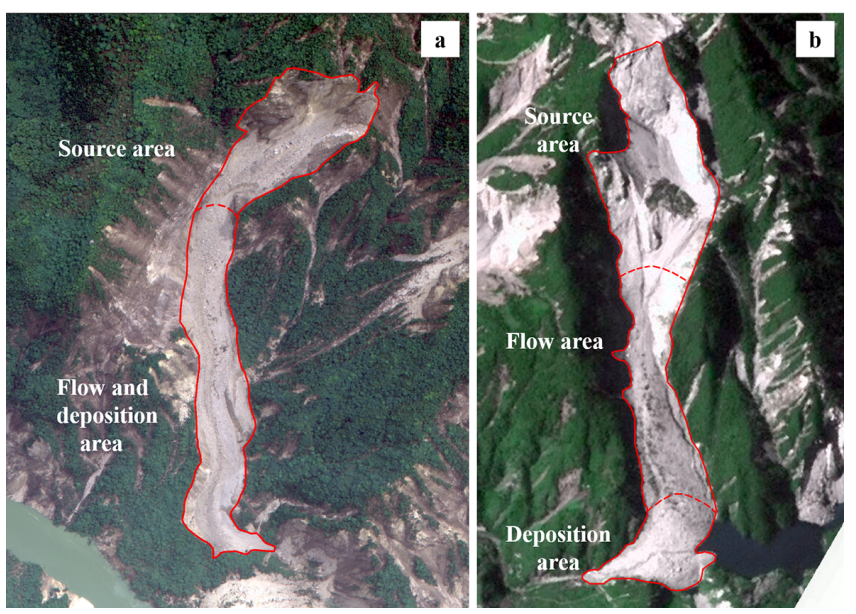

Figure 2. Remote sensing images of two channelized rock avalanches triggered by the Wenchuan earthquake. (a) Changtan rock avalanche (no. 21 in Table 2); (b) Laoyingyan rock avalanche, which is river-blocked.

This study selected 38 channelized rock avalanches induced by the Wenchuan earthquake to study the relations between travel distance and influential factors. These rock avalanches occurred along the seismogenic YingxiuBeichuan fault; the distance to the fault ranged from $0 \mathrm{~m}$ $\sim 21300 \mathrm{~m}$ with a mean value of $3895 \mathrm{~m}$. Another distribution characteristic was that these rock avalanches mainly clustered on the step overs, bends and distal ends of the seismogenic fault. These distribution characteristics of the large rock avalanches suggested that the occurrence of rock avalanches was associated with very strong earthquake ground motion. The Wolong Station recorded the highest seismic acceleration with the peak ground acceleration reaching $0.948 g$ vertically and $0.958 g$ horizontally (Yu et al., 2009). Locally, the ground motion was high enough to throw rocks into the air.

The lithology of outcropping rock in source areas can be divided to four types: carbonate rock, phyllite, igneous rock and sandstone. The deposit of the rock avalanches in the study area was usually debris with mean particle size as tens of centimeters, which suggests that the sliding masses were intensively fragmented during their movement.

The influence of the local geomorphology on the topography of the rock avalanche depositions can be recognized from remote sensing images after the earthquake. The source area and the transition area of channelized rock avalanches in the study area were somehow easy to be differentiated, as the source area are normally located at the top or upper part of slope, while the flow path (flow or transition area) is partially or fully confined by channels (Fig. 2). 
Table 1. Summarization of statistical relationships indicating landslide mobility in the literature.

\begin{tabular}{|c|c|c|c|c|}
\hline Approach & $\begin{array}{l}\text { Keywords } \\
\text { to characterize } \\
\text { the methods }\end{array}$ & Landslide types & Triggers & Main references \\
\hline \multirow[t]{2}{*}{ Reach angle } & $\log H / L=\mathrm{C}_{1} \log V+\mathrm{C}_{0}$ & $\begin{array}{l}\text { Rockfall/slide/avalanche } \\
\text { and flow-like landslides }\end{array}$ & Unknown & $\begin{array}{l}\text { Scheidegger (1973); } \\
\text { Corominas (1996) }\end{array}$ \\
\hline & $H / L=\mathrm{C}_{1} \tan S+\mathrm{C}_{0}$ & $\begin{array}{l}\text { Soil slides, } \\
\text { snow avalanches }\end{array}$ & Non-seismic & $\begin{array}{l}\text { Hunter and Fell (2003); } \\
\text { Lied and Bakkehøi (1980) }\end{array}$ \\
\hline \multirow[t]{3}{*}{ Travel distance } & $\begin{array}{l}\log L=\mathrm{C}_{1} \mathrm{Rt}+\mathrm{C}_{2} \log V \\
+\mathrm{C}_{3} \sin \mathrm{St}+\mathrm{C}_{0}\end{array}$ & $\begin{array}{l}\text { Rock/soil slides and } \\
\text { rock/debris avalanches, }\end{array}$ & Seismic & Guo et al. (2014) \\
\hline & $\begin{array}{l}\log L=\mathrm{C}_{1} \log H \\
+\mathrm{C}_{2} \log \tan S+\mathrm{C}_{0}\end{array}$ & $\begin{array}{l}\text { Soil landslides } \\
\text { on artificial slopes }\end{array}$ & Human activities & Finlay et al. (1999) \\
\hline & $L=\mathrm{C}_{1} V^{C 2}$ & Debris slides, debris slides & Rainfall & Jaiswal et al. (2011) \\
\hline
\end{tabular}

Note: $\mathrm{C} 0, \mathrm{C} 1, \mathrm{C} 2, \mathrm{C} 3$ are the constants. $L$ is the travel distance. $H$ is the total height. $V$ is the volume. $S$ is the average slope angle while St is the slope transition angle. Rt is the rock type.

\section{Data and method}

\subsection{General consideration}

Various statistical methods have been applied to predict travel distance of landslides, and some popular relationships are summarized in Table 1. The most prevalent one is the equivalent friction coefficient model, which only takes account of landslide volume ( $V$ ) (Scheidegger, 1973). Another well-known model is the statistical $\alpha-\beta$ model in which the maximum runout distance is solely a function of topographic conditions (Lied and Bakkehøi, 1980; Gauer et al., 2010). Finlay et al. (1999) developed some multiple regression models containing slope geometric parameters like slope height and slope angle for the travel-distance prediction of landslides on the artificial slopes upon the horizontal surface. Based on the data of 54 landslides that were relatively open or confined by gentle lateral slope, Guo et al. (2014) established an empirical model for predicting landslide travel distance in the Wenchuan earthquake area and suggested that rock type, landslide volume and slope transition angle (between the failed upper slope and lower slope) play dominant roles on landslide travel distance. It has been increasingly stated that the prediction models of travel distance should adapt to different types of landslides (Corominas, 1996; Fan et al,, 2014).

Moreover, the shape and mobility of rock avalanches are controlled by the local topography. Heim (1932) firstly mentioned the influence of local morphology: the debris masses will undergo different effects with the angle of reach changing, and rock avalanches have to conform to the local morphology regardless of their scale. Abele (1974) summarized four different possibilities of adaptation of the rock avalanche to local morphology. Hsu (1975) noted that a sinuous pathway can reduce runout distance of rock avalanches. Nicoletti and Sorriso-Valvo (1991) inferred that local morphology impacts landslide motion by changing the rate of total energy dissipation along the travel path. To determine the influence of specific channels on the travel distances of rock avalanches, we consider the impacts of the gradient of the upper slopes and lower channels.

Rock avalanches triggered by the Wenchuan earthquake usually initiated from the top or the higher part of slopes possibly due to the altitude amplification effect of earthquake acceleration; therefore the toes of the rupture surface were commonly found in the source area at the upstream of the pre-existing channel (See Fig. 3). When the slope failed, the failed mass traveled a long distance down the channel. The 38 rock avalanches in this study are selected with the criterion that the flow path is partially or fully confined by channels. The volumes of these rock avalanches ranged from 0.4 to $50 \times 10^{6} \mathrm{~m}^{3}$, with horizontal travel distances between 0.58 and $4.00 \mathrm{~km}$. The volume is prior to the area to be put into the travel-distance prediction model as it had much more physical meanings. We introduced total relief as well as the height of source area to probe the influences of the potential energy difference and altitude difference of source mass on the travel distance of the rock avalanches.

\subsection{Data}

The terms and notations of a typical channelized rock avalanche are shown in Fig. 3. The local morphology of a rock avalanche can be divided to three sections: initiated slope (source area), channel (main travel path or flow area) and valley floor (deposition area). When the mass moves over the initiated slope section, it is free from lateral constraints, and the moving mass is able to spread laterally. After entering the channel, the flowing mass is constrained by the two lateral slopes. Finally, the mass may reach a wide valley floor, where it spreads laterally and deposits. The average inclination of the source area and travel path is obtained, while the gradient of valley floor (deposition area) is neglected as it has very little variation. Slope angle $(\alpha)$ denotes the average in- 
Table 2. Data of various factors for establishment of prediction model of rock avalanche travel distance.

\begin{tabular}{|c|c|c|c|c|c|c|c|c|c|c|c|}
\hline Code & $\begin{array}{l}\text { Landslide } \\
\text { name }\end{array}$ & $\begin{array}{r}\text { Longitude, } \\
\left({ }^{\circ} \mathrm{E}\right)\end{array}$ & $\begin{array}{l}\text { Latitude, } \\
\left({ }^{\circ} \mathrm{N}\right)\end{array}$ & $\begin{array}{r}\text { Landslide } \\
\text { area, } \\
A\left(\mathrm{~m}^{2}\right)\end{array}$ & $\begin{array}{c}\text { Landslide } \\
\text { volume, } \\
V\left(\mathrm{~m}^{3}\right)\end{array}$ & $\begin{array}{r}\text { Source area } \\
\text { height, } \\
H s(\mathrm{~m})\end{array}$ & $\begin{array}{r}\text { Slope } \\
\text { angle, } \\
\alpha\left({ }^{\circ}\right)\end{array}$ & $\begin{array}{r}\text { Channel } \\
\text { angle, } \\
\beta\left(^{\circ}\right)\end{array}$ & $\begin{array}{l}\text { Total } \\
\text { relief, } \\
H(\mathrm{~m})\end{array}$ & $\begin{array}{r}\text { Travel } \\
\text { distance, } \\
L(\mathrm{~m})\end{array}$ & Reference \\
\hline 1 & Wenjia Gully & 104.140 & 31.552 & 3000566 & 50000000 & 440 & 26 & 7 & 1320 & 4000 & Xu et al. (2009) \\
\hline 2 & Shuimo Gully & 103.981 & 31.442 & 915608 & 19960000 & 490 & 35 & 10 & 860 & 2000 & \\
\hline 3 & Dawuji & 104.196 & 31.702 & 792190 & 16330000 & 540 & 29 & 13 & 880 & 1900 & \\
\hline 4 & Donghekou & 105.113 & 32.410 & 1283627 & 15000000 & 240 & 25 & 11 & 640 & 2400 & Xu et al. (2009) \\
\hline 5 & Hongshi Gully & 104.130 & 31.624 & 687520 & 13410000 & 290 & 37 & 17 & 1040 & 2700 & \\
\hline 6 & Woqian & 104.964 & 32.308 & 695672 & 12000000 & 330 & 30 & 10 & 560 & 1600 & Xu et al. (2009) \\
\hline 7 & Xiaojiashan & 104.038 & 31.465 & 465899 & 7810000 & 480 & 48 & 24 & 930 & 1350 & \\
\hline 8 & Niumian Gully & 103.456 & 31.044 & 527700 & 7500000 & 320 & 32 & 13 & 800 & 2640 & Xu et al. (2009) \\
\hline 9 & Liqi Gully & 105.207 & 32.169 & 355113 & 5360000 & 360 & 37 & 12 & 650 & 1500 & \\
\hline 10 & Caocaoping & 104.139 & 31.607 & 354046 & 5340000 & 345 & 31 & 17 & 580 & 1340 & \\
\hline 11 & Huoshi Gully & 104.134 & 31.616 & 322155 & 4680000 & 270 & 38 & 17 & 700 & 1320 & \\
\hline 12 & Shibangou & 105.090 & 32.419 & 496983 & 4500000 & 450 & 34 & 9 & 650 & 1800 & Xu et al. (2009) \\
\hline 13 & Xiejiadianzi & 103.841 & 31.298 & 294256 & 4000000 & 400 & 34 & 15 & 720 & 1600 & Xu et al. (2009) \\
\hline 14 & Dashui Gully & 103.675 & 31.199 & 241874 & 3150000 & 320 & 30 & 17 & 560 & 1400 & \\
\hline 15 & Changping & 103.754 & 31.259 & 224645 & 2840000 & 290 & 37 & 16 & 500 & 1200 & \\
\hline 16 & Xiaomuling & 104.102 & 31.613 & 218704 & 2740000 & 175 & 45 & 26 & 710 & 1025 & \\
\hline 17 & Baishuling & 104.385 & 31.807 & 208968 & 2570000 & 335 & 36 & 20 & 620 & 1200 & \\
\hline 18 & Dawan & 104.536 & 31.907 & 203959 & 2480000 & 220 & 28 & 20 & 480 & 1000 & \\
\hline 19 & Xiaojiashan & 104.182 & 31.486 & 198165 & 2385499 & 340 & 44 & 20 & 650 & 1135 & \\
\hline 20 & Shicouzi & 104.918 & 32.243 & 169540 & 1920000 & 260 & 30 & 26 & 640 & 1200 & \\
\hline 21 & Changtan & 104.133 & 31.508 & 151094 & 1640000 & 400 & 33 & 25 & 1050 & 1650 & \\
\hline 22 & Hongmagong & 104.962 & 32.301 & 144683 & 1540000 & 195 & 30 & 14 & 330 & 800 & \\
\hline 23 & Baiguocun & 105.088 & 32.385 & 139800 & 1470000 & 165 & 26 & 12 & 260 & 800 & \\
\hline 24 & Qinglongcun & 105.036 & 32.342 & 134079 & 1390000 & 90 & 21 & 11 & 200 & 600 & \\
\hline 25 & Pengjiashan & 104.546 & 31.930 & 127156 & 1290000 & 200 & 33 & 28 & 580 & 1000 & \\
\hline 26 & Longwancun & 104.571 & 31.922 & 99821 & 920000 & 205 & 31 & 28 & 460 & 860 & \\
\hline 27 & Zhangzhengbo & 105.017 & 32.333 & 99726 & 920000 & 125 & 29 & 15 & 320 & 800 & \\
\hline 28 & Dujiayan & 105.028 & 32.336 & 94769 & 860000 & 100 & 33 & 17 & 400 & 880 & \\
\hline 29 & Madiping & 104.996 & 32.355 & 94632 & 860000 & 140 & 27 & 31 & 395 & 740 & \\
\hline 30 & Yandiaowo & 105.099 & 32.391 & 92128 & 820000 & 145 & 30 & 26 & 390 & 800 & \\
\hline 31 & Chuangzi Gully & 104.085 & 31.518 & 91717 & 820000 & 185 & 35 & 15 & 295 & 670 & \\
\hline 32 & Zhaojiashan & 105.041 & 32.342 & 82329 & 700000 & 115 & 22 & 16 & 280 & 700 & \\
\hline 33 & Weiziping & 105.083 & 32.387 & 74661 & 620000 & 135 & 22 & 18 & 240 & 600 & \\
\hline 34 & Maochongshan 2 & 104.908 & 32.243 & 70251 & 570000 & 160 & 38 & 22 & 500 & 740 & \\
\hline 35 & Waqianshan & 105.049 & 32.376 & 70007 & 560000 & 135 & 24 & 18 & 250 & 620 & \\
\hline 36 & Muhongping & 104.982 & 32.291 & 68288 & 540000 & 175 & 28 & 20 & 420 & 970 & \\
\hline 37 & Dapingshang & 104.542 & 31.889 & 65700 & 520000 & 160 & 34 & 29 & 365 & 640 & \\
\hline 38 & Liushuping 2 & 105.054 & 32.365 & 54810 & 400000 & 150 & 29 & 16 & 240 & 580 & \\
\hline
\end{tabular}

clination of the initiated slope section. Channel angle $(\beta)$ denotes the average inclination of the sectional channel. Source area height $(H s)$ denotes the elevation difference between the crest of the sliding source and the toe of the rupture surface. Total relief $(H)$ is the elevation difference between the crest of the sliding source and the distal end of the debris deposit. Travel distance $(L)$ is the horizontal Euclidean distance between the crest of the sliding source and the distal end of the debris deposit. Landslide area $(A)$ is the source area of the rock avalanche obtained from remote sensing image interpretation. An empirical scaling relationship with different empirical coefficients is frequently used to link the volume and the area of landslides in different areas or with different types, and we chose the one developed by Parker et al. (2011) in the same study area. For some rock avalanches with field measured volume available, we use field measurement data rather than the estimated volume by area. The parameters of 38 rock avalanches are listed in Table 2 .

\subsection{Method}

Travel distance is the most important prediction parameter in rock avalanche hazard evaluation in mountainous areas. Travel-distance prediction of rock avalanche is a complicated issue as it is determined by many different properties of the materials (i.e., grain size distribution and water content), topographical factors, mobility mechanics of failed mass, the confinement attributes of travel path, etc. (Guo et al., 2014). Empirical-statistical methods have long been used as tools to study the mobility of rock avalanche since they are easy to develop and apply, and they are not dependent on knowing the complex physical processes involved in the hypermobility of rock avalanches. Channelized rock avalanches have unique movement paths involving complex, and possibly little-known, physical processes such as grain collisions, fragmentation and entrainment of bed material from the channel sides and bottom. Existing empirical models 


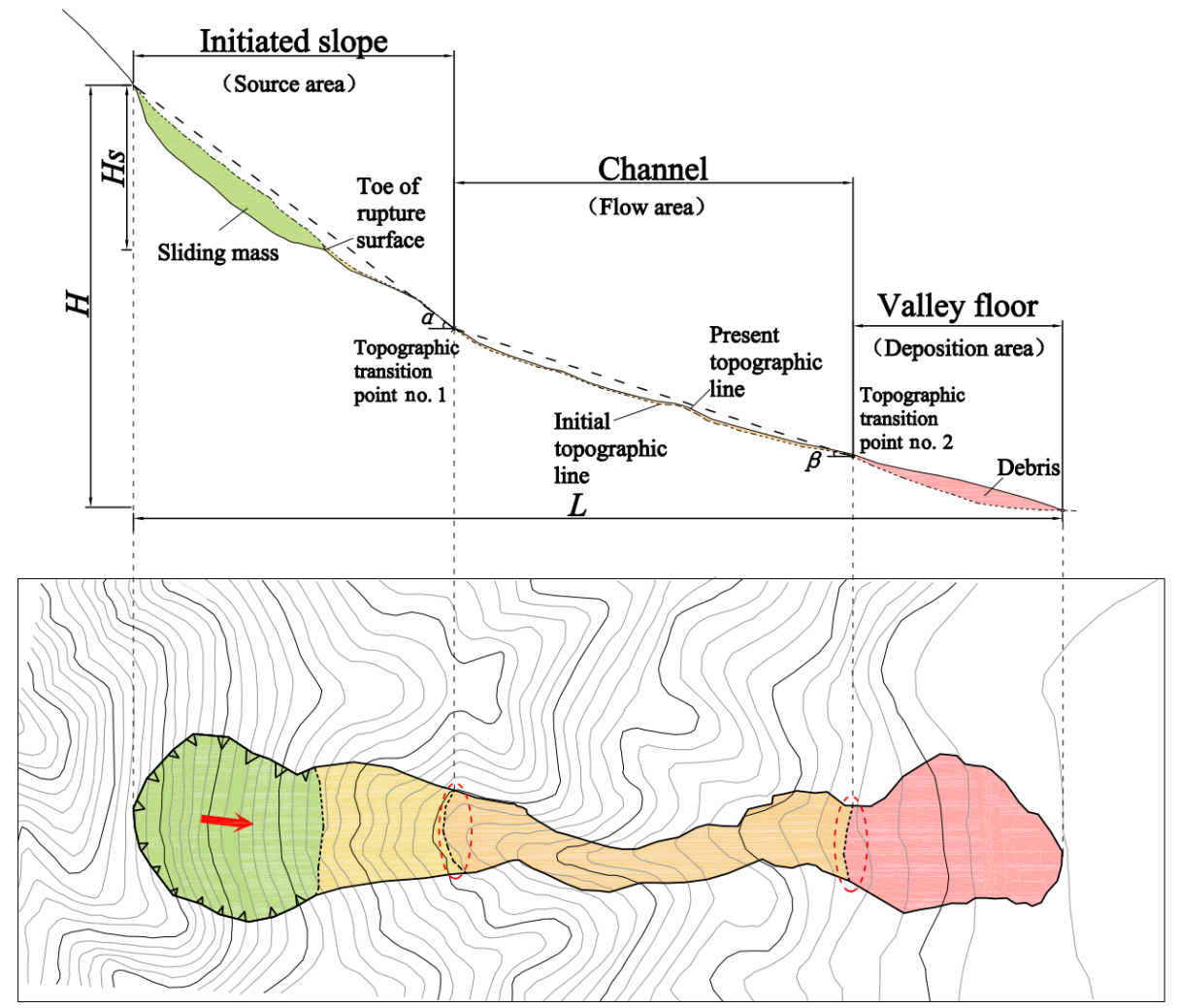

Figure 3. Sketch map of a channelized rock avalanche defining geometric parameters. The red-dashed ellipse indicates the topographic transition dividing the initiated slope, channel and valley floor. The red arrow represents sliding direction of source mass.
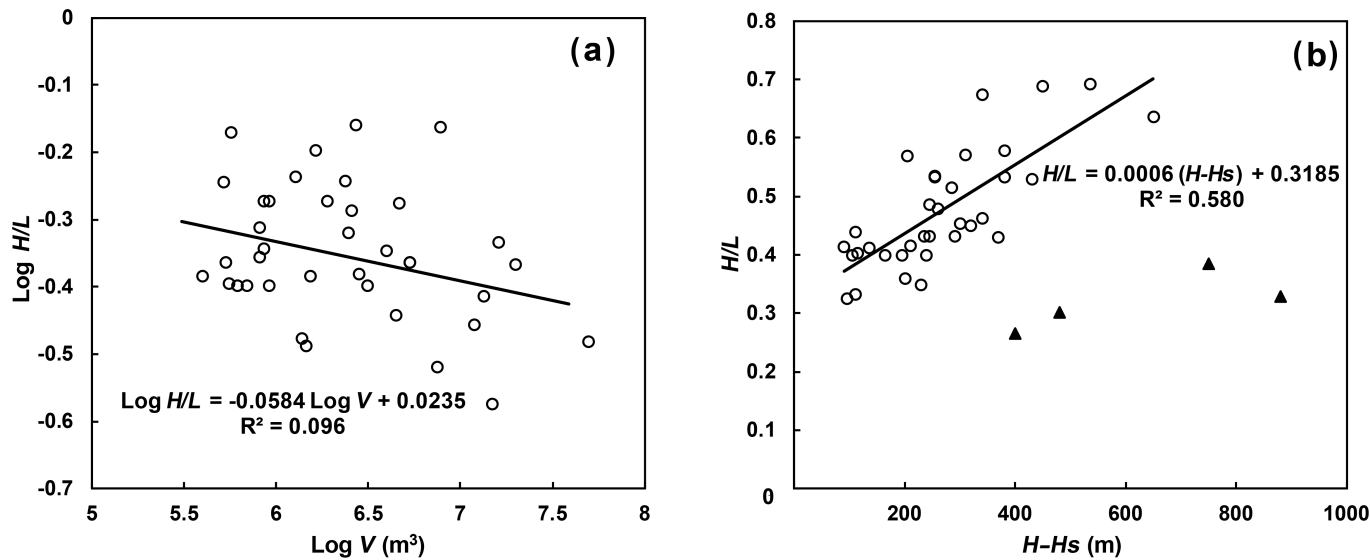

Figure 4. (a) Relationship between reach angle $(H / L)$ and volume $(V)$; (b) relationship between $H / L$ and effective drop height of channelized rock avalanches $(H-H s)$.

have not produced a favorable prediction. The forecasting index system and the prediction model of channelized rock avalanches should be discussed first.

In this paper, we first selected controlling factors on rock avalanche travel distance through correlation analysis. Then we fitted a stepwise multivariate regression model using all significant correlation variables to obtain a best-fit empirical model for landslide travel distance and explored which factors were statistically significant at the same time, as expressed in Eq. (1).

$y=b_{0}+b_{1} x_{1}+b_{2} x_{2}+b_{3} x_{3}+\ldots+b_{n} x_{n}+\varepsilon$,

where $y$ is the predictand ("dependent variable"), e.g., travel distance of rock avalanche, $x_{i}(i=1,2, \ldots, n)$ is the predictor ("independent variable"), $b_{0}$ is the intercept, $b_{i}(i=1,2$, $\ldots, n)$ is the regression coefficient of the corresponding, and 

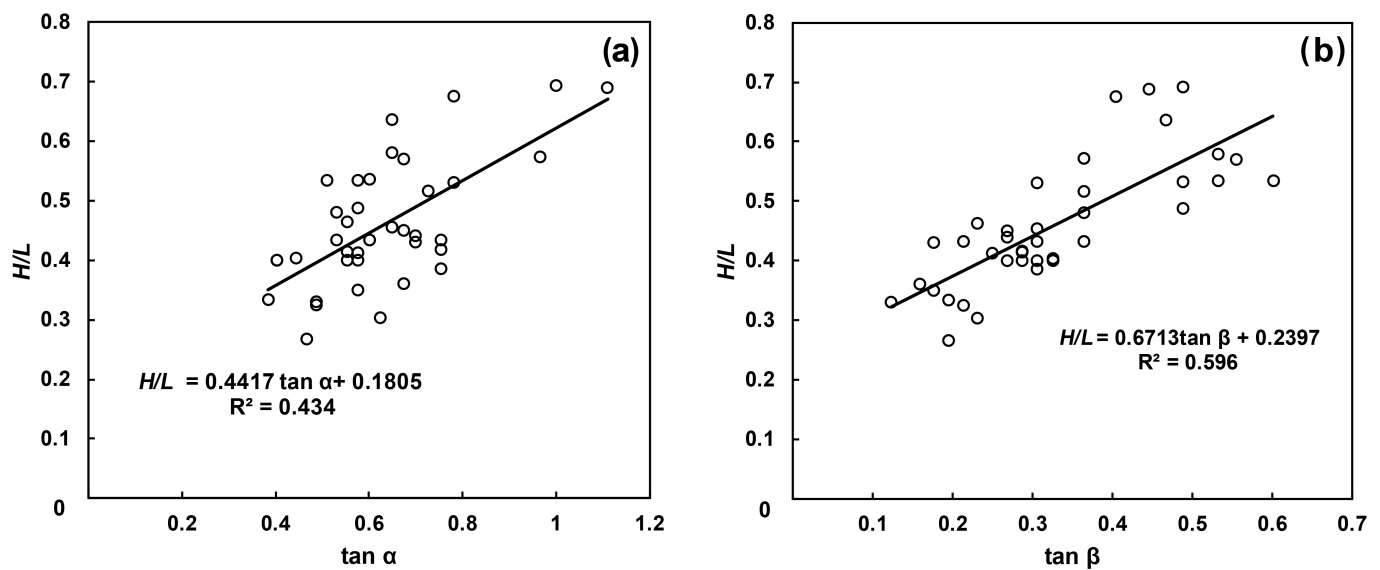

Figure 5. (a) Relationship between reach angle $(H / L)$ and slope angle $(\tan \alpha)$; (b) relationship between $H / L$ and the channel gradient (tan $\beta$ ) of the rock avalanches.

$\varepsilon$ is the residual error, here assumed to be independently and normally distributed. Predictors were added to the regression equation one at a time until there was no significant improvement in parsimonious fit as determined by the adjusted $R^{2}$.

\section{Results and validation}

\subsection{Reach angle of channelized rock avalanches}

Reach angle, also called the apparent coefficient of friction, is a well-known index to express the landslide mobility. It is the angle of the line connecting the crown of the landslide source area to the toe of the displaced mass. This angle is firstly conducted by Heim (1992) in the famous energy-line model as the average coefficient of friction of a sliding mass from initiation to rest. The reach angle is supposed to possess the ability of landslide mobility prediction because of its tendency to decrease with the increase of landslide volume as illustrated by many researchers (Scheidegger, 1973; Corominas, 1996).

In this study, the influence of landslide volume, drop height, slope of the source area and flow path (channel) on the reach angle of the channelized rock avalanches are examined (Figs. 4 and 5). Figure 4a presents $\log$ (volume) vs. $\log$ (reach angle), showing a weak correlation probably due to the limited volume range in our dataset, constrained movement in channel and local morphology of channels. In order to analyze the effect of potential energy on the reach angle, the effective drop height (defined as the total height minus the height of source area) is used instead of the total height to exclude the effect of the superposition of source height and total height. That is especially useful for landslides with large-size initiation but limited travel distance. A significant positive correlation is observed between the reach angle and effective drop height, apart from the four lower scatters in Fig. $4 \mathrm{~b}$. Figure $5 \mathrm{a}$ and $\mathrm{b}$ indicate obvious positive correla-
Table 3. Correlation coefficients of continuous variables listed in Table 2.

\begin{tabular}{lrrrrrrr}
\hline & $A$ & $V$ & $H$ & $H s$ & $\alpha$ & $\beta$ & $L$ \\
\hline$A$ & 1.000 & 0.982 & 0.674 & 0.521 & -0.119 & -0.524 & 0.877 \\
$V$ & - & 1.000 & 0.713 & 0.560 & -0.055 & -0.492 & 0.866 \\
$H$ & - & - & 1.000 & 0.801 & 0.429 & -0.130 & 0.857 \\
$H s$ & - & - & - & 1.000 & 0.399 & -0.323 & 0.675 \\
$\alpha$ & - & - & - & - & 1.000 & 0.264 & 0.082 \\
$\beta$ & - & - & - & - & - & 1.000 & -0.467 \\
$L$ & - & - & - & - & - & - & 1.000 \\
\hline \multicolumn{7}{l}{ Note: the number in italics indicates the two variables are not significantly correlated. }
\end{tabular}

tions between the reach angle with both the slope gradient in source area and channel gradient along the flow path. The large scatter in Figs. 4 and 5 suggests that the reach angle of channelized rock avalanches might be controlled by some other factors, such as local topography rather than volume, but this needs to be further studied.

\subsection{Relationships between travel distance and volume}

Correlation coefficients between different variables and $L$ were calculated first, generating the correlation coefficients matrix shown in Table 3. The significant relevant predictors with the $95 \%$ confidence for travel-distance prediction of channelized rock avalanches are $A, V, H, H s$ and $\beta$, with correlation coefficient of $0.877,0.866,0.857,0.675$ and -0.467 , respectively.

Figure 6 illustrates that the travel distance varies exponentially with $V$ of rock avalanche with an exponential exponent of 0.377. Compared with a compilation of worldwide rock avalanche data (Legros, 2002), the mobility of rock avalanches in our study area is stronger than other non-volcanic landslides (power exponent is 0.25 ) but weaker than volcanic landslides and debris flows (power exponent is 0.39), as shown in Fig. 13. The relation between $L$ and 


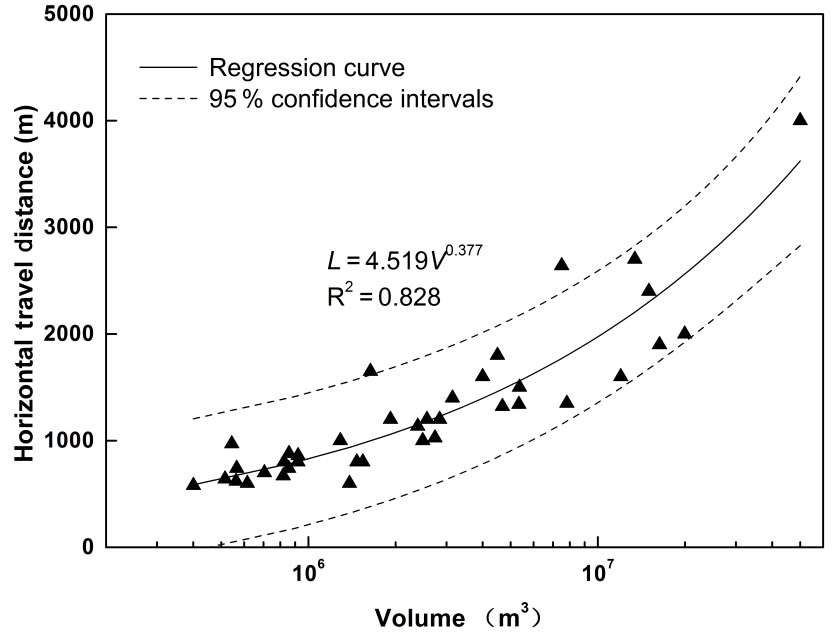

Figure 6. Relationship between horizontal travel distance and volume of channelized rock avalanches.

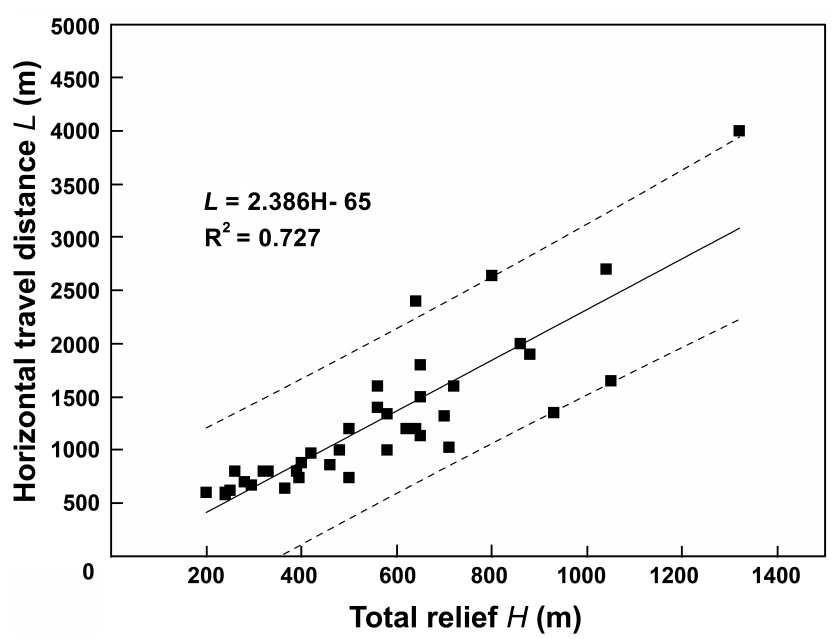

Figure 7. Relationship between horizontal travel distance and total relief of channelized rock avalanches.

$H$ is shown in Fig. 7. The result suggests that the mobility (travel distance) of rock avalanche has a relatively strong linear relationship with $H$. The scale factor is close to 2.4 , which means that the apparent friction coefficient $(H / L)$ for the rock avalanches is approximately 0.42 . This is significantly lower than the commonly observed static coefficient of friction of rock material $(\sim 0.6)$.

\subsection{Multivariate regression model of rock avalanche travel distance}

According to the matrix of correlation coefficients (Table 3), $\alpha$ does not have a significant correlation with $L$ at the $95 \%$ confidence level. Thus this variable could be excluded first during development of the best-fit regression model for travel-distance prediction. Prior to $A, V$ has been consid- ered in the models as it has much more physical meaning. In the end, a stepwise linear multivariate regression technique was applied to find the best-fit travel-distance regression model using the significant relevant predictors including $V, H, H s$ and $\beta$. The best-fit regression equation for traveldistance prediction were derived from the dataset of Table 2 (see Eq. 2), and the coefficient of the variables with $95 \%$ confidence is shown in Table 4.

$$
\begin{aligned}
\log (L) & =0.420+0.079 \log (V)+0.718 \log (H) \\
& -0.365 \log (\tan \beta),
\end{aligned}
$$

where $\log$ is the logarithm of $10, L$ is the predicted travel distance $(\mathrm{m}), V$ is the landslide volume $\left(\mathrm{m}^{3}\right), H$ is the total relief $(\mathrm{m})$ and $\beta$ is the mean gradient of the channel $\left({ }^{\circ}\right)$.

Equation (2) can be transformed to Eq. (3):

$L=2.630 V^{0.079} H^{0.718}(\tan \beta)^{-0.365}$.

The best-fit travel-distance regression equation indicates that the travel distance of channelized rock avalanche is positively correlated with landslide scale (landslide volume) and potential energy loss (total relief) and negatively correlated with channel gradient, which is coherent with the results of correlation analysis in Table 3.

While $H$ will be unknown prior to landslide occurrence, the elevation difference of source area will be available through specific field investigation on a potential rock avalanche area. Hence, we introduced $H s$ and $\alpha$ in replacement of $H$ to the regression model as they have relative high correlation with $H$ (correlation coefficients are 0.801 and 0.429 , respectively). The transformed alternative regression equation is given as Eq. (4) with the coefficient of the variables with $95 \%$ confidence in Table 4 .

$L=3.6 V^{0.303} H s^{0.244}(\tan \alpha)^{-0.115}(\tan \beta)^{0.072}$,

where $L$ is the predicted travel distance (m), $V$ is the landslide volume $\left(\mathrm{m}^{3}\right), H s$ is the height of source area $(\mathrm{m}), \alpha$ is the mean angle of slope segment $\left(^{\circ}\right)$ and $\beta$ is the mean gradient of the channel segment $\left({ }^{\circ}\right)$.

The validity of these two models was evaluated through the significance test leading to the highest $R^{2}$ value and the lowest residual standard error. Table 4 shows the significance values for the prediction model equations. Adjusted $R^{2}$ means adjusted multiple correlation coefficient, which represents the correlation level between the dependent variable and the independent variables. The calculation of adjusted $R^{2}$ considers the number of variables and can be used to compare goodness of fit of different regression models. Adjusted $R^{2}$ of the two regression equations is high, suggesting that the constructed regression models are reliable. The adjusted $R^{2}$ of Eq. (2) is higher than Eq. (4), implying a higher precision for the best-fit regression model. The significance test results on the regression equation suggest the significance of multiple regression equations $\left(F=173.5>F_{0.05}(2.883)\right.$ for 
Table 4. The regression coefficients and results of significance tests of two multivariate regression models.

\begin{tabular}{llrrrrrrrr}
\hline Equations & Coefficients* & Intercept & $\begin{array}{r}\text { Coefficient } \\
\text { of } \log (\mathrm{V})\end{array}$ & $\begin{array}{r}\text { Coefficient } \\
\text { of } \log (H)\end{array}$ & $\begin{array}{r}\text { Coefficient } \\
\text { of } \log (\tan \beta)\end{array}$ & $\begin{array}{r}\text { Coefficient } \\
\text { of } \log (H s)\end{array}$ & $\begin{array}{r}\text { Coefficient } \\
\text { of } \log (\tan \beta)\end{array}$ & $\begin{array}{r}\text { Adjusted } \\
R^{2}\end{array}$ & $\begin{array}{r}F_{\text {stat }} \\
F_{0.05}\end{array}$ \\
\hline Best-fit & LCI & 0.175 & -0.013 & 0.521 & -0.548 & - & - & - & 0.933 \\
Regression & Mean & 0.420 & 0.079 & 0.718 & -0.365 & - & - & -173.5 & 2.883 \\
Equation & UCI & 0.665 & 0.171 & 0.914 & -0.182 & - & -0.464 & \\
Alternative & LCI & 0.110 & 0.199 & - & -0.165 & -0.002 & -0.115 & 0.840 \\
Regression & Mean & 0.561 & 0.303 & - & 0.072 & 0.244 & 49.5 & 2.659 \\
Equation & UCI & 1.012 & 0.407 & - & 0.308 & 0.489 & 0.233 & \\
\hline "Coefficients" of each variable has three kinds: LCI is the lower bound of the coefficients with $95 \%$ confidence; mean is the mean value of the coefficients; UCI is the upper bound of the
\end{tabular}
coefficients with $95 \%$ confidence.

Table 5. Background parameters and predicted values of eight rock avalanches in the same area used for validation.

\begin{tabular}{|c|c|c|c|c|c|c|c|c|c|c|c|c|c|}
\hline $\begin{array}{l}\text { Landslide } \\
\text { name }\end{array}$ & Longitude & Latitude & Triggers* & $\begin{array}{r}V \\
\left(10^{4} \mathrm{~m}^{3}\right)\end{array}$ & $\begin{array}{r}\alpha \\
\left({ }^{\circ}\right)\end{array}$ & $\begin{array}{r}B \\
\left({ }^{\circ}\right)\end{array}$ & $\begin{array}{l}H s \\
(\mathrm{~m})\end{array}$ & $\begin{array}{r}H \\
(\mathrm{~m})\end{array}$ & $\begin{array}{r}L \\
(\mathrm{~m})\end{array}$ & $\begin{array}{r}L_{(3)}^{\prime}{ }^{* *} \\
(\mathrm{~m})\end{array}$ & $\begin{array}{l}\text { Error } \\
(\%)\end{array}$ & $\begin{array}{r}L_{(4)}^{\prime}{ }^{* * *} \\
(\mathrm{~m})\end{array}$ & $\begin{array}{r}\text { Error } \\
(\%)\end{array}$ \\
\hline Pianqiaozi & 104.370 & 31.822 & WCEQ & 8.8 & 35 & 19 & 153 & 205 & 372 & 436 & 17.2 & 373 & 0.3 \\
\hline Yangjiayan & 104.328 & 31.755 & WCEQ & 25.4 & 41 & 23 & 164 & 304 & 518 & 583 & 12.5 & 518 & 0.1 \\
\hline Shanshulin & 103.508 & 31.181 & WCEQ & 27.9 & 34 & 25 & 340 & 433 & 715 & 731 & 2.3 & 660 & -7.6 \\
\hline Fuyangou & 103.501 & 31.422 & WCEQ & 71.9 & 38 & 28 & 385 & 530 & 763 & 869 & 13.8 & 900 & 17.9 \\
\hline Dayanbeng 1 & 102.762 & 30.179 & LSEQ & 100 & 53 & 10 & 254 & 424 & 1267 & 1136 & -10.3 & 781 & -38.4 \\
\hline Dayanbeng 2 & 102.761 & 30.178 & LSEQ & 110 & 50 & 8 & 237 & 407 & 1372 & 1208 & -12.0 & 787 & -42.6 \\
\hline Ermanshan & 102.739 & 29.322 & $\mathrm{RF}$ & 100 & 33 & 15 & 148 & 635 & 1370 & 1303 & -4.9 & 767 & -44.0 \\
\hline Wulipo & 103.567 & 30.919 & RF & 150 & 30 & 10 & 135 & 377 & 1260 & 1078 & -14.4 & 833 & -33.9 \\
\hline
\end{tabular}

"Triggers" is the triggering condition of rock avalanches: WCEQ represents the 2008 Wenchuan $M_{\mathrm{S}} 8.0$ earthquake; LSEQ represents the 2013 Lushan $M_{\mathrm{S}} 7.0$ earthquake; RF represents the rock avalanche induced by heavy rainfall. $L^{\prime}{ }_{(3)}$ and $L^{\prime}{ }_{(4)}$ indicate the predicted travel distance estimated by Eqs. (3) and (4), respectively.
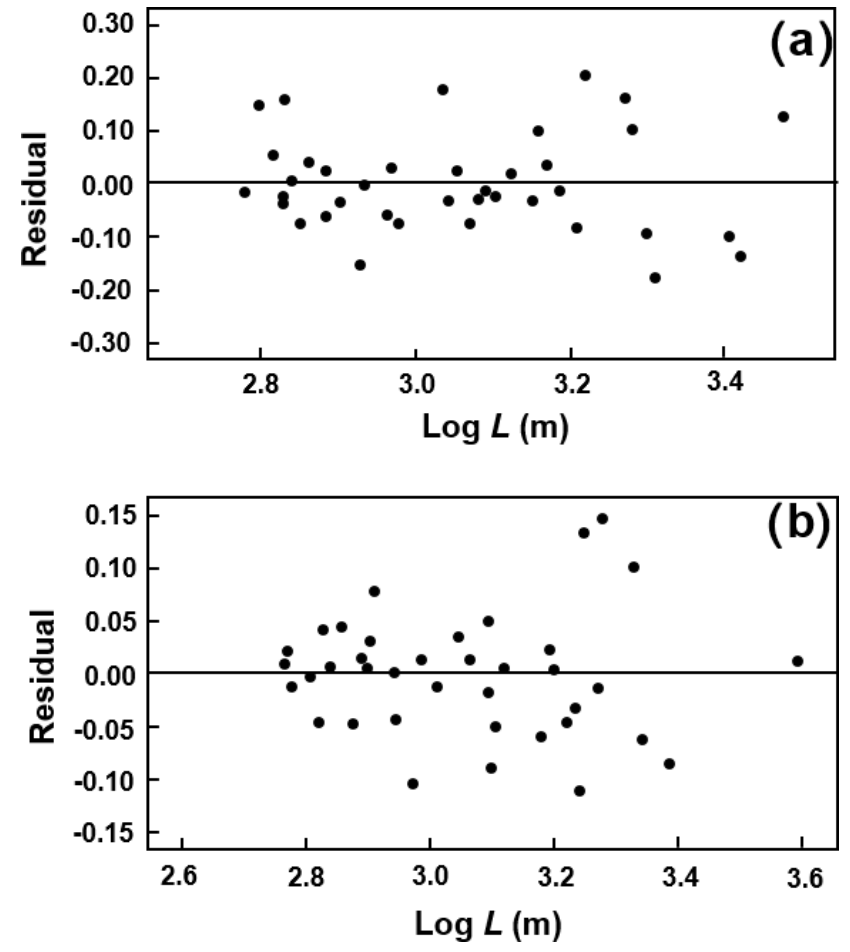

Figure 8. Residual plots for the two multivariate regression models: Fig. 9a is for Eq. (2) and Fig. 9b is for Eq. (4).
Eq. $2 ; F=49.5>F_{0.05}(2.659)$ for Eq. 4). Figure $8 \mathrm{a}$ and b show the distributions of the residuals in relation to the observed travel distance estimated by using Eqs. (2) and (4). Both plots illustrate normality, constant variance and absence of trends in the residuals.

Figure 9 compares the predicted travel distances estimated by using Eqs. (2) and (4) with the observed ones. It suggests that the predicted values of the samples are close to the observed ones. Where $L$ exceeds $2000 \mathrm{~m}$, the predicted travel distance calculated by using two models are lower than actual one, with relatively large residual error.

\subsection{Validation}

The regression equations were tested using an independent sample validation dataset of eight rock avalanches in the same area induced by three different kinds of triggers: $2008 M_{\mathrm{S}} 8.0$ Wenchuan earthquake, $2013 M_{\mathrm{S}} 7.0$ Lushan earthquake and heavy rainfall (Table 5). The volume of these samples ranged from $88 \times 10^{3}$ to $1.5 \times 10^{6} \mathrm{~m}^{3}$ and travel distance from 372 to $1372 \mathrm{~m}$. The background parameters and the predicted values of each avalanche are listed in Table 5. The relative errors between the predicted values estimated by using Eq. (3) and observed values of the travel distance of the rock avalanches, $\mid L_{\text {predicted }}-$ $L_{\text {observed }} \mid / L_{\text {observed }} \times 100 \%$, are between -14.4 and $17.2 \%$, while the relative errors are -44.0 and $17.9 \%$ for Eq. (4). On the whole, these two regression models achieved acceptable 


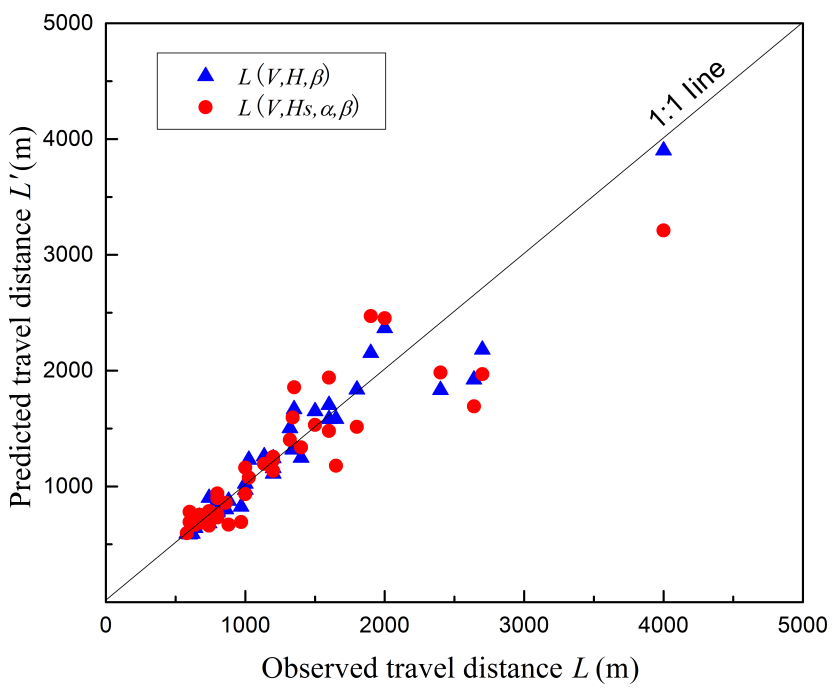

Figure 9. The comparison between observed and predicted travel distance for the two multivariate regression models.

prediction accuracy for preliminary forecasting of travel distance of rock avalanches in rugged mountainous areas. The best-fit regression model appeared to provide greater precision than the alternative model. Regarding the influence of triggers on the travel distance of the channelized rock avalanches, those triggered by rainfall and the Lushan earthquake seemed to be more mobile. It is inferred that the former difference is due to the high water content in failed mass induced by rainfall. A possible reason why two rock avalanches triggered in the Lushan earthquake traveled farther may be the structural weakening of slope rock mass during the 2008 Wenchuan earthquake in the study area.

\section{Discussion}

\subsection{Prediction for travel distance of channelized rock avalanche}

The results of our analysis of the dataset indicate that the mobility (travel distance) of channelized rock avalanche is positively correlated with landslide volume and total relief but negatively correlated with channel gradient. As Fig. 6 shows, the travel distance of channelized rock avalanche would rapidly increase with volume of rock avalanche enlarged. Such a high correlation between landslide volume and travel distance implies that the travel distance of channelized rock avalanche is dominated by the spreading of the slide mass (Davies et al., 1999; Staron and Lajeunesse, 2009). The high positive correlation between total relief and travel distance is for two reasons: the larger the total relief is, the more kinetic energy the slide mass could obtain and the further it could travel (Legros, 2002). The channel gradient is highly correlated with the $H / L$ ratio as shown in
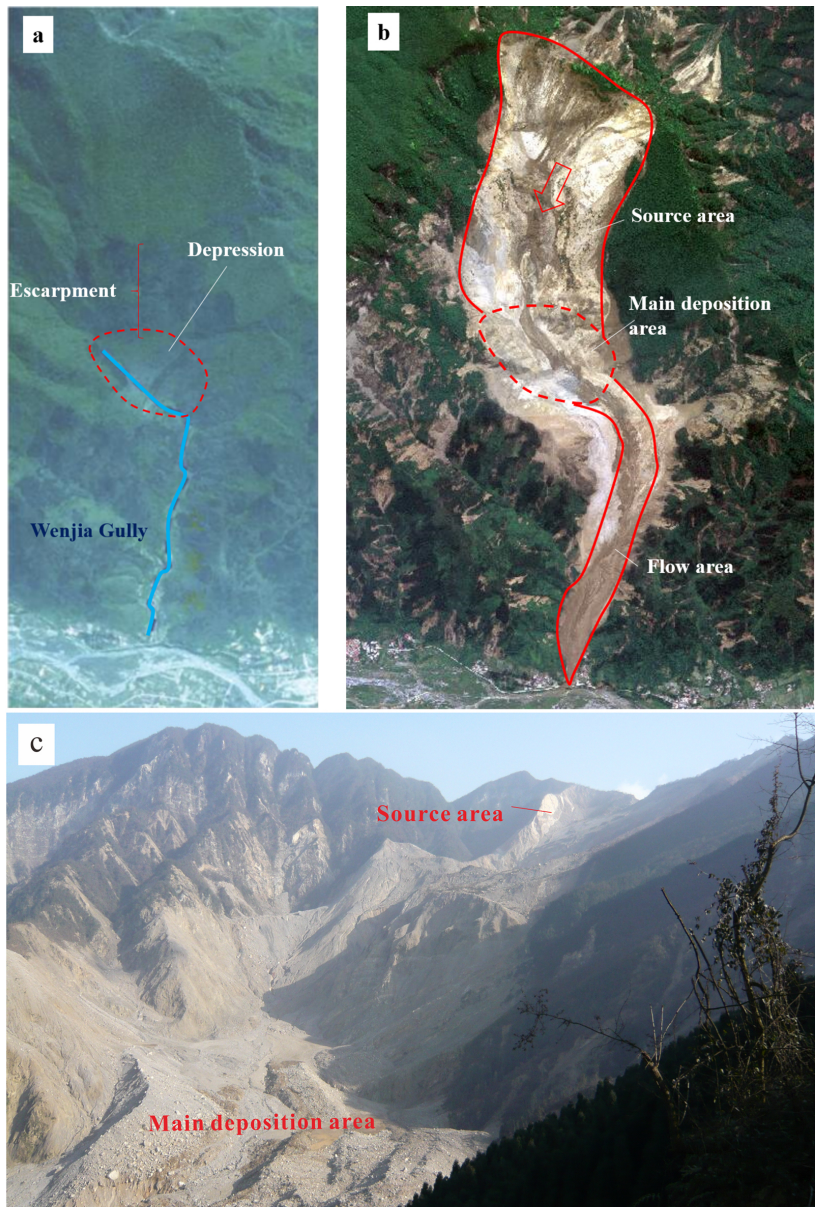

Figure 10. Sketch map of flow capacity of channel affecting on the travel distance of the Wenjia Gully channelized rock avalanche: (a) before the earthquake; (b) after the earthquake; (c) photo taken on deposition platform after the earthquake. The red arrow shows the sliding direction of source mass. The red dotted line in (a) indicates the original depression on the travel path of the rock avalanche, where debris deposition of about 30 million $\mathrm{m}^{3}$ was stored after the earthquake (shown in $\mathbf{b}$ ); more detailed information is shown in (c).

Fig. 5b, which actually represents the apparent friction coefficient along the flow path similar to the definition of angle of reach by Heim (1992). This is probably the reason for the negative correlation between travel distance and channel gradient, as the decrease of channel gradient means the decrease of static friction coefficient and the increase of landslide volume and mobility (Figs. 4a and 12).

The residual analysis result demonstrates that the projection process in the early motion stage will significantly enlarge the travel distance of rock avalanches. The projection phenomenon was observed in the Wenchuan earthquake region by Huang et al. (2011), defined as the thrown out or projectile motion of slope material due to site amplification effect of seismic wave causing the peak ground acceleration 

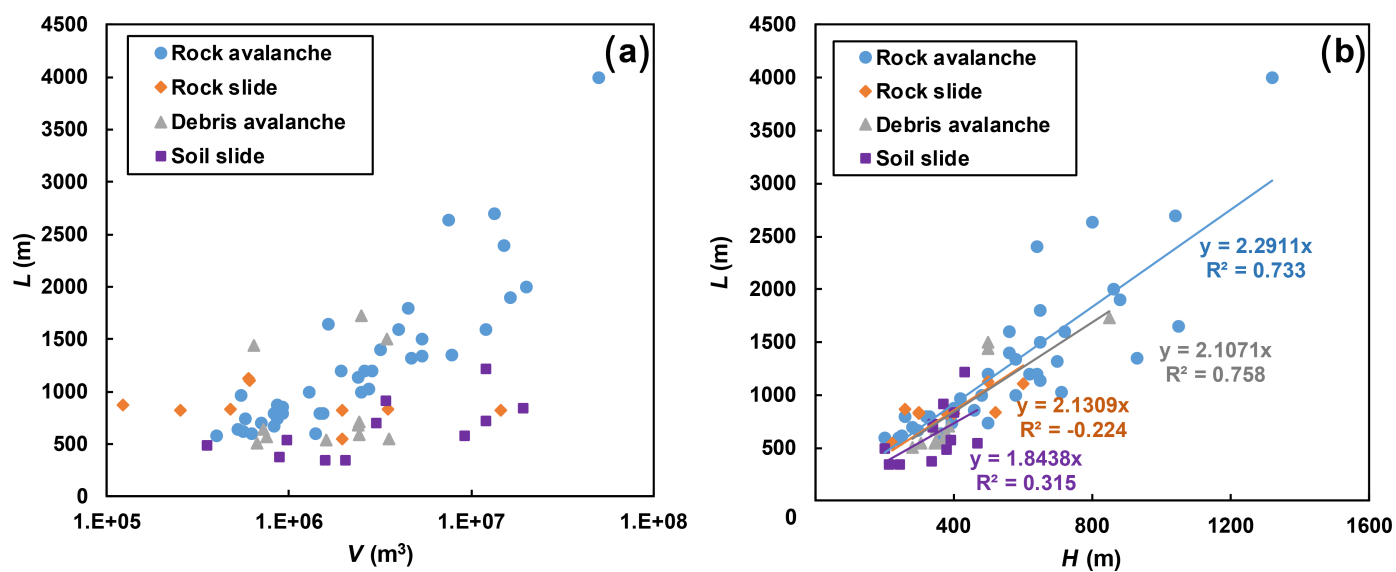

Figure 11. Relationship between the volume and travel distance (a) and between the total height and travel distance (b) of different-type landslides triggered by the Wenchuan earthquake (rockslide, debris avalanche and soil slide data are from Guo et al., 2014).

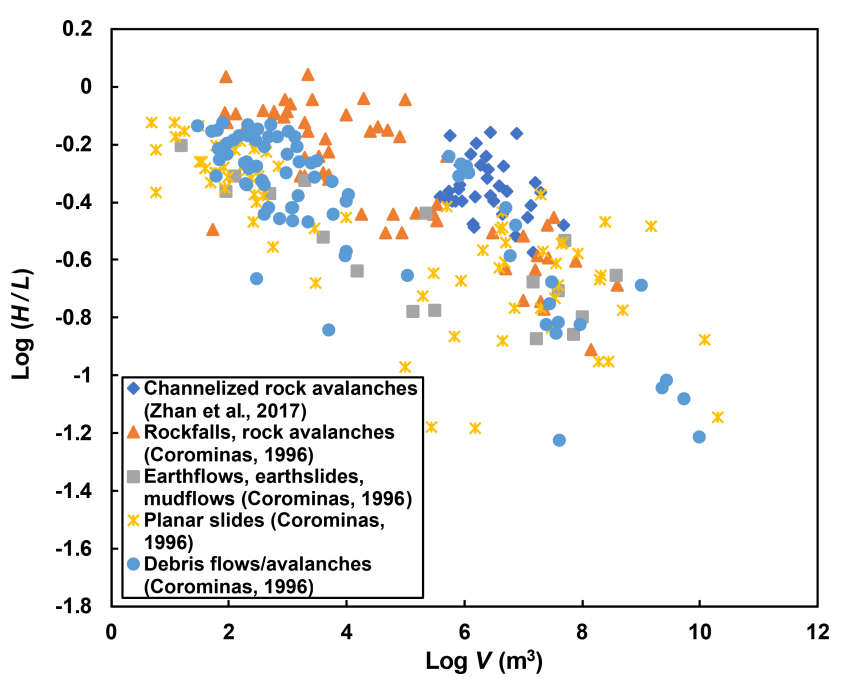

Figure 12. Relationship between the volume and $H / L$ ratio of different-type landslides from the worldwide dataset (Corominas, 1996).

to be larger than $9.8 \mathrm{~m} \mathrm{~s}^{-2}$. The nature of this phenomenon is suggested to be involved with transformation of motion mode from sliding to flowing due to collision and fragmentation effects after the projection (Davies et al., 1999). Furthermore, the degree of fragmentation of failed mass should have remarkable influence on the travel distance of rock avalanche, and other factors changing the fragmentation degree should be further studied, such as earthquake effect, geologic structure and rock type.

\subsection{The mobility of channelized rock avalanches}

The mobility of landslides is influenced by a variety of factors, such as topography, landslide size, material type, landslide type and water content. The important role of topographical constrains on the landslide mobility can be indi-

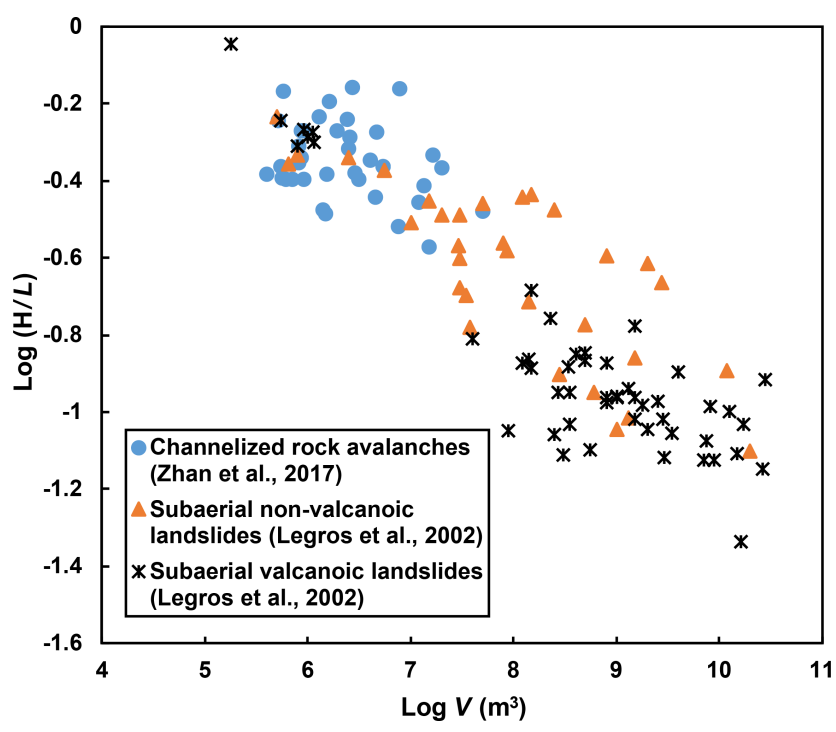

Figure 13. Relationship between the volume and $H / L$ ratio of different-type landslides from the worldwide dataset (Legros, 2002).

cated from the high positive correlation of reach angle with effective drop height, slope gradient and channel gradient (see Figs. 4 and 5). Besides, some microtopography like turns (changes of channel flow direction), drop cliff and broad depression along the landslide travel path will influence the motion and deposition of rock avalanches remarkably. The rock avalanches corresponding with the four large bias scatter in Fig. 4b are the Wenjia Gully, Hongshi Gully, Niumian Gully and Donghekou rock avalanche, whose flow paths have cliffs in the upper end of channels with notable drop heights of 260 , 150,60 and $160 \mathrm{~m}$, respectively, according to field investigations. Moreover, fluidization characteristics such as superelevation near curve transitions can be found in the channel section of these four rock avalanches. This steep microtopogra- 
phy will enlarge the mobility of rock avalanches because the sliding mass will undergo the drop, collision and fragmentation effects in the early motion stage, which will facilitate motion-mode transformation from sliding to flowing. This transformation will enhance the mobility of rock avalanches traveling a much longer distance than predicted. Attention also must be paid to the broad depression along the channel, which can contain a large amount of debris mass and therefore curb the travel distance of channelized rock avalanches. For example, in the Wenjia Gully almost half of the total volume of the rock avalanche was deposited at the beginning of the channel (see Fig. 10c), leading to a shorter travel distance than expected.

To investigate the influence of landslide types on the landslide mobility, we compile our dataset with the dataset created by Guo et al. (2014), as it contains the data of 32 landslides with other types (debris avalanches, rockslides, soil slides) triggered by the Wenchuan earthquake. We plot the relationship between $L$ with $V$ and $H$, respectively, for different landslide types (see Fig. 11a and b). As shown in Fig. 11, rock avalanches have the strongest mobility while soil slides show the weakest one, and the mobility of rockslides is approximate to the mobility of debris avalanches. Through comparison with the worldwide datasets by using the reach angle as the mobility index (see Figs. 12 and 13), our dataset shows a consistent tendency with the worldwide datasets presented by Corominas (1996) and Legros (2002). Our dataset could contribute to the worldwide database by filling the gap of rock avalanches.

The common triggers of landslides are earthquakes and rainfall. The influence of triggers on landslide distribution has been well studied, but the effect of triggers on the landslide mobility still constitutes a gap in scientific knowledge. Zhang et al. (2013) indicated that rock avalanches triggered by earthquakes have a slightly lower mobility than those not triggered by earthquakes, and rock avalanches close to the seismic fault do not always have a higher mobility even when a rock avalanche near the seismic fault is subjected to higher ground accelerations. Guo et al. (2014) also mentioned that the seismic acceleration has less influence than rock type, sliding volume, slope transition angle and slope height on landslide travel distance. According to Table 5, two rainfall-induced rock avalanches show stronger mobility than earthquake-induced ones. The rock avalanches induced by rainfall express a stronger mobility than the earthquakeinduced ones may due to lubrication effect of water. However, a detailed study on the influence of triggers on the landslide mobility is required.

\section{Conclusions}

A channelized rock avalanche refers to a rock avalanche with a flow path confined between valley walls. Relevant detailed data on 38 channelized rock avalanches triggered by Wenchuan earthquake were collected by remote sensing, field investigation and literature review. The results of correlation and regression analysis revealed that the movement of channelized rock avalanches is dominated by the spreading of the failed mass. Landslide volume, total relief and channel angle had predominant effects, playing a dominating role in the on travel distance of channelized rock avalanches. Stepwise multivariate regression was used to develop a nonlinear best-fit travel-distance prediction model for the channelized rock avalanches. An alternative multivariate regression model was also built. The reliability of the two models was tested by an independent validation dataset of eight rock avalanches in the same area and produced good results, meeting the requirements for preliminary evaluation of travel distance for channelized rock avalanches in the Wenchuan earthquake area.

Data availability. Data from Guo et al. (2014) in Fig. 11 are available at https://doi.org/10.1007/s10346-013-0444-y. Data from Corominas (1996) in Fig. 12 are available at https://doi.org/10.1139/t96-005. Data from Legros (2002) in Fig. 13 are available at https://doi.org/10.1016/S0013-7952(01)00090-4. Data used for constructing the runout regression models are available in the Supplement.

\section{The Supplement related to this article is available online at https://doi.org/10.5194/nhess-17-833-2017- supplement.}

Competing interests. The authors declare that they have no conflict of interest.

Acknowledgements. This work was supported by the Fund for International Cooperation (NSFC-RCUK_NERC), Resilience to Earthquake-induced landslide risk in China (grant no. 41661134010), the Young Scientists Fund of the National Natural Science Foundation of China (grant no. 41302241), the Fund for Creative Research Groups of China (grant no. 41521002), The authors thank Mauri McSaveney for his constructive comments and editing the English the paper.

Edited by: T. Glade

Reviewed by: T. W. J. van Asch, H.-B. Havenith, and M. Mergili

\section{References}

Abele, G.: Bergstürze in den Alpen - ihre Verbreitung, Morphologie und Folgeerscheinungen, Wiss. Alpenvereinshefte, 25, 247 pp., 1974.

Corominas, J.: The angle of reach as a mobility index for small and large landslides, Can. Geotech. J., 33, 260-271, 1996. 
Davies, T. R., McSaveney, M. J., and Hodgson, K. A.: A fragmentation-spreading model for long-runout rock avalanches, Can. Geotech. J., 36, 1096-1110, 1999.

Fan, X., Rossiter, D. G., Westen, C. J., Xu, Q., and Görüm, T.: Empirical prediction of coseismic landslide dam formation, Earth Surf. Proc. Land., 39, 1913-1926, 2014.

Finlay, P. J., Mostyn, G. R., and Fell, R.: Landslide risk assessment: prediction of travel distance, Can. Geotech. J., 36, 556562, 1999.

Gauer, P., Kronholm, K., Lied, K., Kristensen, K., and Bakkehøi, $\mathrm{S}$ : Can we learn more from the data underlying the statistical $\alpha-$ $\beta$ model with respect to the dynamical behavior of avalanches?, Cold Reg. Sci. Technol., 62, 42-54, 2010.

Guo, D., Hamada, M., He, C., Wang, Y., and Zou, Y.: An empirical model for landslide travel distance prediction in Wenchuan earthquake area, Landslides, 11, 281-291, 2014.

Heim, A.: Bergsturz und menschenleben (No. 20), Fretz and Wasmuth, 1932.

Huang, R. Q., Xu, Q., and Huo, J. J.: Mechanism and Geomechanics Models of Landslides Triggered by 5.12 Wenchuan Earthquake, J. Mountain Sci., 8, 200-210, 2011.

Hungr, O., Evans, S. G., Bovis, M. J., and Hutchinson, J. N.: A review of the classification of landslides of the flow type, Environ. Eng. Geosci., 7, 221-238, 2001.

Hungr, O. and McDougall, S.: Two numerical models for landslide dynamic analysis, Comput. Geosci., 35, 978-992, 2009.

Hungr, O., Leroueil, S., and Picarelli, L.: The Varnes classification of landslide types, an update, Landslides, 11, 167-194, 2014.

Hunter, G. and Fell, R.: Travel distance angle for "rapid" landslides in constructed and natural soil slopes, Can. Geotech. J., 40, 1123-1141, 2003.

Hsü K J.: Catastrophic debris streams (sturzstroms) generated by rockfalls, Geol. Soc. Am. Bull., 86, 129-140, 1975.

Jaiswal, P., van Westen, C. J., and Jetten, V.: Quantitative estimation of landslide risk from rapid debris slides on natural slopes in the Nilgiri hills, India, Nat. Hazards Earth Syst. Sci., 11, 1723-1743, https://doi.org/10.5194/nhess-11-1723-2011, 2011.

Legros, F.: The mobility of long-runout landslides, Eng. Geol., 63, 301-331, 2002.

Lied, K. and Bakkehøi, S.: Empirical calculations of snowavalanche run-out distance based on topographic parameters, J. Glaciol., 26, 165-177, 1980.

Lo, C. M., Lin, M. L., Tang, C. L., and Hu, J. C.: A kinematic model of the Hsiaolin landslide calibrated to the morphology of the landslide deposit, Eng. Geol., 123, 22-39, 2011.
Mergili, M., Krenn, J., and Chu, H.-J.: r.randomwalk v1, a multifunctional conceptual tool for mass movement routing, Geosci. Model Dev., 8, 4027-4043, https://doi.org/10.5194/gmd-8-40272015, 2015.

Nicoletti, P. G. and Sorriso-Valvo, M.: Geomorphic controls of the shape and mobility of rock avalanches, Geol. Soc. Am. Bull., 103, 1365-1373, 1991.

Parker, R. N., Densmore, A. L., Rosser, N. J., De Michele, M., Li, Y., Huang, R., Petley, D. N., and Whadcoat, S.: Mass wasting triggered by the 2008 Wenchuan earthquake is greater than orogenic growth, Nat. Geosci., 4, 449-452, 2011.

Pastor, M., Haddad, B., Sorbino, G., Cuomo, S., and Drempetic, V.: A depth-integrated, coupled SPH model for flow-like landslides and related phenomena, International Journal for numerical and analytical methods in geomechanics, 33, 143-172, 2009.

Qi, S., Xu, Q., Zhang, B., Zhou, Y., Lan, H., and Li, L.: Source characteristics of long runout rock avalanches triggered by the 2008 Wenchuan earthquake, China, J. Asian Earth Sci., 40, 896906, 2011.

Sassa, K.: Geotechnical model for the motion of landslides, in: Proceedings of the 5th International Symposium on Landslide, edited by: Balkema, A. A., Rotterdam, 37-55, 1988.

Scheidegger, A. E.: On the prediction of the reach and velocity of catastrophic landslides, Rock Mech. Rock Eng., 5, 231-236, 1973.

Staron, L. and Lajeunesse, E.: Understanding how volume affects the mobility of dry debris flows, Geophys. Res. Lett., 36, 91100, 2009.

Van Westen, C. J., Van Asch, T. W., and Soeters, R.: Landslide hazard and risk zonation-why is it still so difficult?, B. Eng. Geol. Environ., 65, 167-184, 2006.

$\mathrm{Xu}$, Q., Pei, X. J., and Huang, R. Q.: Large-scale landslides induced by the Wenchuan earthquake, Science, Beijing, 2009 (in Chinese).

Yu, H., Wang, D, Yang, Y., Xie, Q., Jiang, W., and Zhou, B.: The preliminary analysis of strong ground motion records from the $\mathrm{M}_{S}$ 8.0 Wenchuan Earthquake, Journal of Earthquake Engineering and Engineering Vibration, 29, 1-13, 2009.

Zhang, M. and Yin, Y.: Dynamics, mobility-controlling factors and transport mechanisms of rapid long-runout rock avalanches in China, Eng. Geol., 167, 37-58, 2013. 